\title{
Effect of antenatal exercises on pulmonary functions and labour outcome in uncomplicated primigravida women: a randomized controlled study
}

\section{Pooja Jain $^{1} *$, Himsweta Srivastava ${ }^{1}$, Neerja Goel ${ }^{1}$, Farah Khaliq $^{2}$, Pooja Dewan ${ }^{3}$, Renu Sharma $^{4}$, Vishnu Bhartiya ${ }^{1}$}

\author{
${ }^{1}$ Department of Obstetrics \& Gynaecology, UCMS \& GTB Hospital, Delhi, India \\ ${ }^{2}$ Department of Physiology, UCMS \& GTB Hospital, Delhi, India \\ ${ }^{3}$ Department of Paediatrics, UCMS \& GTB Hospital, Delhi, India \\ ${ }^{4}$ Department of Orthopaedics, UCMS \& GTB Hospital, Delhi, India
}

Received: 13 August 2015

Accepted: 02 September 2015

\section{*Correspondence:}

Dr. Pooja Jain,

E-mail: dr.poojajain0107@gmail.com

Copyright: (c) the author(s), publisher and licensee Medip Academy. This is an open-access article distributed under the terms of the Creative Commons Attribution Non-Commercial License, which permits unrestricted non-commercial use, distribution, and reproduction in any medium, provided the original work is properly cited.

\begin{abstract}
Background: Physical fitness could influence pulmonary functions, labour and neonatal outcomes in pregnancy. The present study was undertaken to evaluate the effect of antenatal exercises on pulmonary functions and labour outcomes.

Methods: Study included 122 uncomplicated primigravida in age group of $18-35$ years at $24^{\text {th }}-28^{\text {th }}$ week of gestation were randomly allocated into study and control groups. Antenatal exercises were performed by study group for a minimum of 3 days a week for 20 minute duration till their delivery. Pulmonary function tests (PFTs) were done for all subjects at $24^{\text {th }}$ week of gestation and after $36^{\text {th }}$ week of gestation.

Results: A significant improvement in FEV1, FVC, FEF25-75\%, MEF50\%, MIF50\% and MVV between 24 \& 36 weeks was observed in the study group after exercises. In study group $85.24 \%$ patients had spontaneous onset of labour, $14.8 \%$ patients had induction of labour as compared to $75.4 \%$ and $24.6 \%$ respectively in control group, however statistically insignificant. In the study group $41.67 \%$ patients did not require augmentation compared to $22.95 \%$ in the control group. In study group $13.11 \%$ patients had meconium stained liquor which was significantly less in comparison to $41 \%$ patients in the control group. Mean duration of first, second and third stage of labour was shorter in study group than control group. In study group $96.72 \%$ had normal and none had instrumental vaginal delivery compared to $88.52 \%$ and $6.6 \%$ from control group respectively. Caesarean section rate was $3.3 \%$ in study group and $4.9 \%$ in control group. APGAR score was normal in all the neonates. Fetal weight gain, birth weight, birth length and head circumference was significantly higher and NICU stay was significantly lesser in study group compared to control group.

Conclusions: Antenatal exercises lead to improvement of pulmonary functions and hence labour and neonatal outcomes
\end{abstract}

Keywords: Antenatal exercises; Pulmonary functions; Neonatal outcomes; Labour outcomes 


\section{INTRODUCTION}

Childbirth is a natural phenomenon and one of the most beautiful, exciting, and critical experiences of a woman, yet it can be very challenging and demanding for women who are not physically and/or mentally prepared. ${ }^{1}$ Pregnancy is associated with many physiological and anatomical changes in all systems. Changes in respiratory physiology are due to increasing size of fetus with advancing gestation which constitutes a mechanical impediment to normal process of ventilation. ${ }^{2}$ Among respiratory changes there is a $4 \mathrm{~cm}$ rise in diaphragm and widening of subcostal angle by $2 \mathrm{~cm}^{3}$ Minute ventilation increases by $50 \%$ largely due to increased tidal volume. ${ }^{4}$ Peak expiratory flow rates (PEFR), residual volume, functional residual capacity (FRC), expiratory reserve volume (ERV) and total lung volume gets reduced as pregnancy advances. Airway conductance increases, pulmonary resistance decreases while lung compliance remains unaffected. Respiratory rate, forced vital capacity and maximum breathing capacity are unchanged, with a $10-20 \%$ increase in baseline $\mathrm{O}_{2}$ consumption. ${ }^{3,4}$ All these changes make respiratory diseases more serious during pregnancy. This is the reason why understanding of expected or desired changes in pulmonary function tests is important to know how disease affects pregnancy or vice versa.

Pulmonary function tests (PFT) permit an accurate and reproducible assessment of the functional state of respiratory system and allow quantification of the severity of disease.

A sedentary life style and being overweight increases risk of several obstetrical complications, still birth and neonatal deaths ${ }^{5}$.Physical fitness could influence course of labour outcome as pregnancy induces many metabolic and hormonal changes that influence uterine contractility and endurance ${ }^{5}$. American College of Obstetricians and gynaecologists (ACOG), in January 2002 recommended 30 minutes or more of moderate exercise on most, if not all, days of week for pregnant women in the absence of either medical or obstetric complications ${ }^{4}$. Even the centre for Disease Control and Prevention and the American College for Sports Medicine (CDC-ACSM) recommends the same ${ }^{6}$. Currently, only $15.1 \%$ of pregnant women exercise at the recommended level which is significantly lower than the general population's $45 \%^{7}$

Although a comprehensive review of literature on the effect of antenatal exercises on labour outcome is available, but due to methodological pitfalls and smaller sample size, data provided is insufficient and inconsistent to infer any beneficial or detrimental effect on maternal and fetal outcome ${ }^{8}$. In this context, purpose of this study is to evaluate effect of antenatal exercises on pulmonary functions and labour outcome.

\section{METHODS}

\section{Study design}

Study was an Open randomized controlled trial carried out in Department of Obstetrics \& Gynaecology, Paediatrics, Physiology and Physiotherapy Unit of orthopedics. Subjects were recruited from Gynaecology OPD of UCMS \& GTB Hospital Delhi.

\section{Subjects}

Uncomplicated primigravida in age group of 18-35 years at $24^{\text {th }}$ to $28^{\text {th }}$ week of gestation were recruited from antenatal clinic of the gynaecology OPD after taking detailed history, examination, written consent and ruling out exclusion criteria were randomly allocated into two equal groups, study and control.

\section{Exclusion criteria}

- Chronic medical diseases (respiratory disease, heart disease, uncontrolled diabetes mellitus, hypertension, tuberculosis, epilepsy, thyroid disorders).

- Ante partum haemorrhage.

- Severe anaemia.

- Intrauterine growth restriction.

- Pregnancy induced hypertension.

- Preterm labour.

- Premature rupture of membranes.

- Multiple gestations at risk for preterm labour.

- Incompetent cervix / Cerclage.

- Morbid obesity /Extreme underweight (BMI <12).

- Orthopaedic limitations.

- Smokers.

PFTs were carried out using SIBELMED DATOSPIR 120B precision portable spirometer with built in computer program using standard laboratory methods in the department of Physiology. Antenatal exercises were performed by study group for a minimum of 3 days a week for 20 minute duration till their delivery. PFTs were done for all subjects at 24th week of gestation and after $36^{\text {th }}$ week of gestation. Control group did not perform any antenatal exercises. After 12 weeks post exercise PFT's were repeated for all subjects. Follow up of all the subjects was done every 4 weeks till 32 weeks, then after every 2 weeks till 36 weeks and thereafter weekly till their delivery. Labour and neonatal outcomes were closely monitored in labour room.

\section{Statistical analysis}

Baseline pulmonary function tests and parameters related to labour outcome (quantitative data) between study and control groups were analysed by unpaired " $\mathrm{t}$ " test and for qualitative data Chi-square or Fisher exact test were used. Repeated measures analyses of co-variance were used for intra and inter group pulmonary function tests 
comparisons. All analysis was done by SPSS-20 statistical software.

\section{RESULTS}

Table 1: Comparison of pulmonary functions at 24 and 36 weeks in study group.

\begin{tabular}{|llll|} 
Variable & $\begin{array}{l}\text { At } 24 \\
\text { Weeks } \\
\text { Mean } \pm \text { SD }\end{array}$ & $\begin{array}{l}\text { At } 36 \\
\text { Weeks } \\
\text { Mean } \pm \text { SD }\end{array}$ & $\begin{array}{l}\text { P- } \\
\text { value }\end{array}$ \\
\hline FEV $_{1}(\mathrm{~L})$ & $1.61 \pm 0.32$ & $2.19 \pm 0.38$ & $0.00^{*}$ \\
\hline FVC $(\mathrm{L})$ & $1.72 \pm 0.39$ & $2.47 \pm 0.39$ & $0.00^{*}$ \\
\hline $\mathrm{FEV}_{1} / \mathrm{FVC}(\%)$ & $89.44 \pm 8.82$ & $89.19 \pm 8.39$ & 0.80 \\
\hline $\mathrm{VC}(\mathrm{L})$ & $2.32 \pm 0.59$ & $2.51 \pm 0.60$ & 0.13 \\
\hline TV $(\mathrm{L})$ & $1.26 \pm 0.49$ & $1.62 \pm 0.42$ & $0.00^{*}$ \\
\hline ERV $(\mathrm{L})$ & $0.82 \pm 0.54$ & $0.72 \pm 0.3$ & 0.059 \\
\hline PEFR (L/Sec) & $2.02 \pm 0.84$ & $2.12 \pm 0.84$ & 0.97 \\
\hline $\begin{array}{l}\text { MEF50\% } \\
\text { (L/Sec) }\end{array}$ & $1.62 \pm 0.64$ & $2.23 \pm 0.67$ & $0.00^{*}$ \\
\hline MIF50\% (L/Sec) & $1.46 \pm 0.50$ & $1.72 \pm 0.52$ & $0.00^{*}$ \\
\hline $\begin{array}{l}\text { FEF25-75\% } \\
\text { (L/Sec) }\end{array}$ & $1.61 \pm 0.61$ & $2.07 \pm 0.51$ & $0.00^{*}$ \\
\hline MVV (L/Min) & $80.48 \pm 14.65$ & $83.90 \pm 10.75$ & $0.01^{*}$ \\
\hline $\begin{array}{l}* \mathrm{p} \\
\text { value<0.05 }\end{array}$ & & & \\
\hline
\end{tabular}

Table 2: Comparison of pulmonary functions at 24 and 36 weeks in control group.

\begin{tabular}{|llll|} 
Variable & $\begin{array}{l}\text { At } 24 \\
\text { Weeks } \\
\text { Mean } \pm \text { SD }\end{array}$ & $\begin{array}{l}\text { At } 36 \\
\text { Weeks } \\
\text { Mean } \pm \\
\text { SD }\end{array}$ & $\begin{array}{l}\text { P- } \\
\text { value }\end{array}$ \\
& $1.59 \pm 0.28$ & $1.62 \pm 0.2$ & 0.19 \\
\hline FEV $_{1}(\mathrm{~L})$ & $1.76 \pm 0.25$ & $1.76 \pm 0.2$ & 0.94 \\
\hline FVC $(\mathrm{L})^{\text {FEV }}$ /FVC (\%) & $90.54 \pm 10.94$ & $92.42 \pm 6.55$ & 0.11 \\
\hline VC (L) & $2.32 \pm 0.6$ & $2.35 \pm 0.72$ & 0.29 \\
\hline TV (L) & $1.2 \pm 0.32$ & $1.24 \pm 0.3$ & 0.34 \\
\hline ERV (L) & $0.68 \pm 0.33$ & $0.66 \pm 0.31$ & 0.51 \\
\hline PEFR(L/Sec) & $2.04 \pm 0.68$ & $1.64 \pm 0.55$ & $0.00^{*}$ \\
\hline $\begin{array}{l}\text { MEF50\% } \\
\text { (L/Sec) }\end{array}$ & $1.59 \pm 0.55$ & $1.48 \pm 0.51$ & 0.08 \\
\hline $\begin{array}{l}\text { MIF50\% } \\
\text { (L/Sec) }\end{array}$ & $1.33 \pm 0.61$ & $1.25 \pm 0.35$ & 0.43 \\
\hline MVV (L/Min) & $75.44 \pm 17.8$ & $72.27 \pm 15.6$ & $0.007^{*}$ \\
\hline $\begin{array}{l}\text { FEF25-75\% } \\
\text { (L/Sec) }\end{array}$ & $1.58 \pm 0.49$ & $1.48 \pm 0.42$ & 0.07 \\
\hline $\begin{array}{l}* p \\
\text { value<0.05 }\end{array}$ & & & \\
\hline
\end{tabular}

Comparison of age, weight, height and BMI between control and study group were statistically insignificant at 24 weeks. The pulmonary function parameters were statistically insignificant in the two groups at 24 weeks.
Mean change in $\mathrm{FEV}_{1}, \mathrm{FVC}$ and $\mathrm{FEV}_{1} / \mathrm{FVC}$, Peak Expiratory Flow Rate (PEFR), mid expiratory flow rate (MEF50\%), mid inspiratory flow rate (MIF50\%), Forced expiratory flow rate (FEF25-75\%) and Maximum Voluntary Ventilation (MVV) were statistically significant between both groups when compared between $24 \& 36$ weeks of gestation. $\mathrm{FEV}_{1}, \mathrm{FVC}, \mathrm{TV}, \mathrm{MEF} 50 \%$, MIF50\%, FEF25-75\% and MVV were statistically significant in study group between 24 and 36 weeks. While PEFR and MVV were significantly decreased in control group between 24 and 36 weeks.

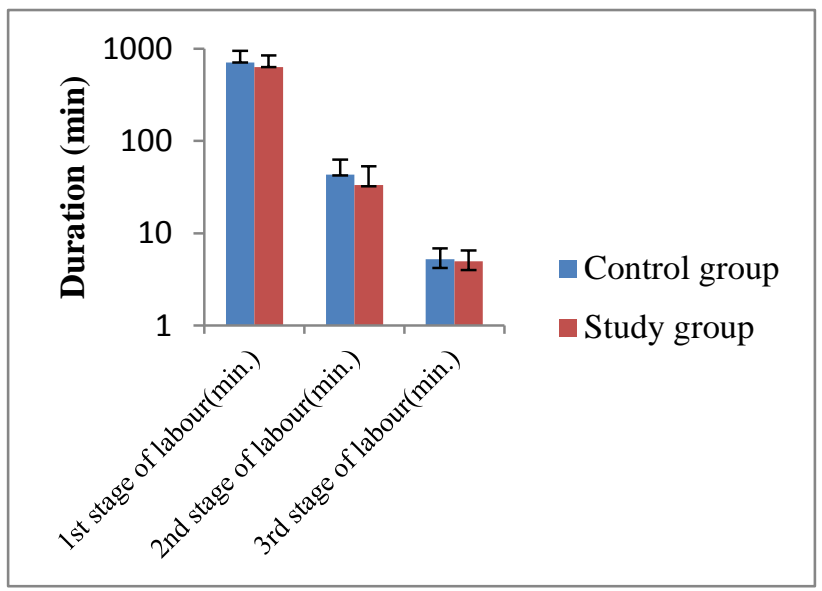

Figure 1: Comparison of duration of labour between control and study groups.

Mean gestational age was similar in the two groups $(38.71 \pm 1.38$ weeks, in Control group and $38.77 \pm 1.22$ weeks, in Study group). Rates of spontaneous and induced labour and mode of delivery in control and study group was statistically insignificant except for need of augmentation and presence of meconium stained liquor which was significant. Statistically significant difference in mean \pm SD for duration of second stage of labour was observed but insignificant difference for first and third stage. Fetal weight gain, birth weight, birth length and head circumference were all found significantly higher in study group than control group. Median APGAR score was same in both the groups at $1 \mathrm{~min}$ and $5 \mathrm{~min}$ but were found to be statistically significant at 1 minute. NICU stay was significantly reduced in study group.

\section{DISCUSSION}

In the present study Forced expiratory volume $\left(\mathrm{FEV}_{1}\right)$, forced vital capacity (FVC), and tidal volume (TV), Mid expiratory flow rate (MEF50\%), Mid inspiratory flow rate (MIF50\%), Forced expiratory flow rate (FEF25$75 \%$ ), Maximum voluntary ventilation (MVV) all had shown significant improvement at 36 weeks after performing antenatal exercises for a period of 12 weeks. Peak expiratory flow rate (PEFR) and $\mathrm{FEV}_{1} / \mathrm{FVC}$ were comparable at 24 and 36 weeks in study group and were insignificant. ERV showed a decrement at 36 weeks compared to 24 weeks and was statistically insignificant. 
Vital capacity improved at 36 weeks but not significantly. Similar results on $\mathrm{FEV}_{1}$ and FVC were found in study conducted by Shashikala L and Ravipati Sarath on effect of exercise on pulmonary functions on CPEd students. ${ }^{9}$ In a study by Grindheim $\mathrm{G}$ et al both FVC and FVC\% increased significantly after 14-16 weeks of gestation $(\mathrm{P}=0.001)$, as was the case for both $\mathrm{PEF}$ and $\mathrm{PEF} \%$ $(\mathrm{P}<0.001)$ which correlates with the present study. ${ }^{10}$ In the present study Forced expiratory volume in $1^{\text {st }}$ second $\left(\mathrm{FEV}_{1}\right)$, Forced Vital Capacity (FVC) and $\mathrm{FEV}_{1} / \mathrm{FVC}$, Vital Capacity (VC), Tidal volume (TV) of control group at 36 weeks had shown a small increment in values compared to 24 weeks and were found to be statistically insignificant. This result is in accordance with a study conducted by Puranik BM et al (1994) which showed that FVC and $\mathrm{FEV}_{1}$ remained unchanged throughout pregnancy with slight variations observed that were statistically insignificant. ${ }^{11}$ Unchanged VC was reported by some whereas decline in $\mathrm{VC}$ and rise in $\mathrm{VC}$ was also noted. ${ }^{11}$ Conflicting results could be due to observations on different subjects from different socio-economic status at different periods of gestation and postpartum period. ${ }^{11}$ Study by Puranik et al also showed an increment in tidal volume that was statistically very highly significant. Increased tidal volume during pregnancy observed may be due to smooth muscle relaxation; a direct effect of progesterone increasing the sensitivity of respiratory centre to carbon dioxide. The altered thoracic configuration also contributes. In the present study a small decrement was seen in expiratory reserve volume (ERV) at 36 weeks which was found to be statistically insignificant. Peak expiratory flow rate (PEFR) and Maximum voluntary ventilation (MVV) had shown a significant decline in values at 36 weeks compared to 24 weeks in subjects not doing antenatal exercise. Study by Puranik et al and sroczynski et al also showed a significant decline in ERV. ${ }^{11,12}$

Table 3: Intergroup comparison of the change in pulmonary function tests at $24 \& 36$ weeks of gestation.

\begin{tabular}{|lllll|}
\hline Variable & $\begin{array}{l}\text { Control group } \\
\text { Mean } \pm \text { SD }\end{array}$ & $\begin{array}{l}\text { Study group } \\
\text { Mean } \pm \text { SD }\end{array}$ & $\begin{array}{l}\text { Change (95\% } \\
\text { Confidence Interval) } \\
\text { after baseline adjustment }\end{array}$ & P-value \\
\hline FEV $_{1}(\mathrm{~L})$ & $0.0308 \pm 0.184$ & $0.340 \pm 0.279$ & $0.384(0.297-0.470)$ & $0.00^{*}$ \\
\hline FVC $(\mathrm{L})$ & $-0.0016 \pm 0.19$ & $0.377 \pm 0.315$ & $0.495(0.401-0.590)$ & $0.00^{*}$ \\
\hline FEV 1 /FVC $(\%)$ & $1.874 \pm 9.04$ & $-0.256 \pm 7.91$ & $-2.767(-5.02-0.511)$ & $0.01^{*}$ \\
\hline VC $(\mathrm{L})$ & $0.128 \pm 0.44$ & $0.186 \pm 0.57$ & $0.106(-0.073-0.286)$ & 0.24 \\
\hline TV $(\mathrm{L})$ & $0.244 \pm 0.29$ & $0.258 \pm 0.32$ & $0.076(-0.021-0.173)$ & 0.12 \\
\hline ERV $(\mathrm{L})$ & $-0.020 \pm 0.24$ & $-0.101 \pm 0.41$ & $0.001(-0.083-0.085)$ & 0.98 \\
\hline PEFR $(\mathrm{L} / \mathrm{sec})$ & $-0.400 \pm 0.41$ & $0.002 \pm 0.594$ & $0.539(0.364-0.713)$ & $0.00^{*}$ \\
\hline MEF50\% (L/sec) & $-0.116 \pm 0.47$ & $0.305 \pm 0.377$ & $0.508(0.360-0.656)$ & $0.00^{*}$ \\
\hline MIF50\% (L/sec) & $-0.08 \pm 0.60$ & $0.263 \pm 0.44$ & $0.174(0.032-0.316)$ & $0.017^{*}$ \\
\hline FEF25-75\% (L/sec) & $-0.095 \pm 0.45$ & $0.256 \pm 0.48$ & $0.466(0.327-0.605)$ & $0.00^{*}$ \\
\hline MVV(L/Min) & $-3.16 \pm 8.91$ & $3.41 \pm 10.53$ & $8.30(5.38-11.22)$ & $0.00^{*}$ \\
\hline${ }^{*}$ p value $<0.05$ & & & & \\
\hline
\end{tabular}

The decline in ERV observed during pregnancy might have occurred due to decreased negativity of intrapleural pressure brought about by upward displacement of diaphragm by enlarged uterus. Another important cause for the decline is attenuation or reduction in contraction power of expiratory muscles due to the stretching of the abdominal wall with the progress of pregnancy. ${ }^{11,13}$ The decline in PEFR during pregnancy occurs suggestively due to lesser force of contraction of main expiratory muscles like anterior abdominal muscles and internal intercostal muscles. ${ }^{9}$

Harirah HM et al, Neeraj et al and Deshpande et al also had reported a significant decline in PEFR with increasing gestation. ${ }^{2,14,15}$ A study by Lata $\mathrm{G}$ et al also had reported a significant decline in mean values of Peak expiratory flow rate (PEFR) and Maximum voluntary ventilation (MVV). ${ }^{16} \mathrm{MVV}$ decreases during pregnancy indicating a mechanical inhibition of chest. The decreased MVV may also be attributed to an increased oxygen requirement per unit of work done in the respiratory muscles. ${ }^{16}$

Mid expiratory flow rate (MEF50\%) and Forced expiratory flow rate (FEF25-75\%) also showed a significant improvement at 36 weeks compared to 24 weeks except for Mid inspiratory flow rate (MIF50\%) which showed a small insignificant decline. A study by Sroczynski T et al showed increased Tidal volume (TV), vital capacity (VC), Mid expiratory flow rate (MEF50\%), Forced expiratory flow rate (FEF25-75\%), and Mid inspiratory flow rate (MIF50\%) in pregnancy. Exercises performed by study group encouraged pulmonary circulation and thoracic expansion and also strengthened the anterior abdominal wall muscles thus improving their respiratory functions. 


\section{Labour outcomes}

Majority of patients in both the groups were of term gestation. Preterm births were $6.5 \%$ in control group and $3.27 \%$ in study group. Post term pregnancies were $15 \%$ in control group and $24.5 \%$ in study group. Mean gestational age was 38 weeks in both control and study group which was statistically insignificant. Barakat $\mathrm{R}$ and Dias et al also didn't find any differences regarding gestational age at birth. ${ }^{17,18}$ Median maternal weight was more in study group than control group which was found to be statistically significant. A study by Price BB et al showed no significant differences in weight gain during pregnancy. ${ }^{19}$ Onset of labour was spontaneous in $85.24 \%$ of patients in the study group in comparison with $75.4 \%$ of patients in control group. In study group $14.8 \%$ patients had induction of labour as compared to $24.6 \%$ in control group however comparison was found to be statistically insignificant. Beckmann CR et al reported that exercising women were more likely to have spontaneous vaginal delivery. $^{20}$

Table 4: Comparison of labour parameters between control and study groups.

\begin{tabular}{|llll|}
\hline $\begin{array}{l}\text { Labour } \\
\text { outcome }\end{array}$ & $\begin{array}{l}\text { Control } \\
\text { group } \\
\text { (\% of } \\
\text { patients) }\end{array}$ & $\begin{array}{l}\text { Study } \\
\text { group } \\
\text { patients) }\end{array}$ & $\begin{array}{l}\text { P- } \\
\text { Valu } \\
\text { pat }\end{array}$ \\
\hline $\begin{array}{l}\text { Spontaneous } \\
\text { labour }\end{array}$ & $75.4 \%$ & $85.24 \%$ & 0.25 \\
\hline $\begin{array}{l}\text { Induction of } \\
\text { labour }\end{array}$ & $24.6 \%$ & $14.8 \%$ & 0.25 \\
\hline $\begin{array}{l}\text { Augmentation } \\
\text { not required }\end{array}$ & $22.95 \%$ & $41.67 \%$ & $0.03 *$ \\
\hline $\begin{array}{l}\text { Meconium } \\
\text { stained liquor }\end{array}$ & $41 \%$ & $13.11 \%$ & $0.01 *$ \\
\hline $\begin{array}{l}\text { Normal } \\
\text { vaginal } \\
\text { delivery }\end{array}$ & $88.52 \%$ & $96.72 \%$ & 0.16 \\
\hline $\begin{array}{l}\text { Instrumental } \\
\text { vaginal } \\
\text { delivery }\end{array}$ & $6.6 \%$ & $0 \%$ & 0.11 \\
\hline $\begin{array}{l}\text { Caesarean } \\
\text { section }\end{array}$ & $4.9 \%$ & $3.3 \%$ & 1.00 \\
\hline
\end{tabular}

In the study group $41.67 \%$ patients did not require augmentation as compared to only $22.95 \%$ in the control group which was found to be statistically significant. Beckmann CR et al also reported lesser need of oxytocin augmentation. $^{20}$ Meconium stained liquor was less frequent in the study group $(13.11 \%)$ as compared to control group (41\%) which was found to be statistically significant, similar results shown in a study by Clapp JF. ${ }^{21}$

Mean duration of first stage was shorter in study group (630.18 $\pm 212.04 \mathrm{~min}$.) compared to control group (708.47 $\pm 241.47 \mathrm{~min}$.) which was found to be statistically insignificant. Lila Sabbaghian Rad et al and Beckmann CR et al reported similar results. ${ }^{20}$

In the present study duration of second stage of labour was shorter in study group (43.12 $\pm 19.6 \mathrm{~min})$ as compared to control group $(33.42 \pm 19.81 \mathrm{~min})$ which was found to be statistically significant. ClappJF ${ }^{21}$ and Beckmann CR et al showed similar results. In study group (96.72\%) and control group $(88.52 \%)$ had vaginal delivery. Instrumental vaginal delivery rate was $6.6 \%$ in control group compared to none in study group. Caesarean section rate was $3.3 \%$ in study group and $4.9 \%$ in control group. Clapp JF showed a lower incidence of operative vaginal and abdominal delivery in exercising women compared to controls. ${ }^{21}$ Similar results were shown by Lila Sabbaghian Rad et al and Price BB et al, S Forouhari et al and Melzer et al, Bungum et al and Magann et al. 1,19,22-25

Table 5. Comparison of neonatal parameters between control and study groups.

\begin{tabular}{|lll|l|}
\hline $\begin{array}{l}\text { Neonatal } \\
\text { outcomes }\end{array}$ & $\begin{array}{l}\text { Control } \\
\text { Group }\end{array}$ & $\begin{array}{l}\text { Study } \\
\text { Group }\end{array}$ & P-Value \\
\hline $\begin{array}{l}\text { Fetal weight gain } \\
(\mathrm{kg})\end{array}$ & $\begin{array}{l}1.04 \pm \\
0.16\end{array}$ & $\begin{array}{l}1.29 \pm \\
0.27\end{array}$ & $0.00^{*}$ \\
\hline $\begin{array}{l}\text { Median APGAR } \\
\text { score at 1 minute }\end{array}$ & $\begin{array}{l}9(8- \\
9)\end{array}$ & $9(9-9)$ & $0.018^{*}$ \\
\hline $\begin{array}{l}\text { Median APGAR } \\
\text { score at 5 minute }\end{array}$ & $\begin{array}{l}9(9- \\
9.5)\end{array}$ & $9(9-10)$ & 0.066 \\
\hline Birth weight(kg) & $\begin{array}{l}2.57 \pm \\
0.24\end{array}$ & $\begin{array}{l}2.91 \pm \\
0.38\end{array}$ & $0.00^{*}$ \\
\hline Birth length $(\mathrm{cm})$ & $\begin{array}{l}48.29 \pm \\
1.34\end{array}$ & $\begin{array}{l}49.62 \pm \\
1.22\end{array}$ & $0.00^{*}$ \\
\hline Head & $32.71 \pm$ & $33.38 \pm$ \\
circumference $(\mathrm{cm})$ & 0.75 & 0.88 & $0.00^{*}$ \\
\hline NICU stay $(\%)$ & 49.2 & 14.8 & $0.00^{*}$ \\
\hline p value $<0.05$ & & & \\
\hline
\end{tabular}

First minute APGAR was found to be significantly higher in study group however statistically insignificant at fifth min. Clapp JF also reported less clinical evidence of acute fetal distress in terms of APGAR score in exercising group. ${ }^{29}$ Other studies by Collings et al, Kardel \& Kase et al, Baciuk et al, Melzer et al, Dias et al and S Forouhari et al did not find any differences in APGAR score. ${ }^{18,23,27,30-32}$

Mean birth weight was higher in study group than control group which was found to be statistically significant. Agur et al and Hatch MC et al also reported greater weight among new-borns in their training group. ${ }^{29,33}$ Some authors have stated that fetal growth seems to be influenced by maternal activity, as some investigators have found significantly bigger babies born by moderately trained females compared to non- trained or heavily trained women and antenatal exercises may have a role in improving fetoplacental circulation. ${ }^{23}$ A significant difference was observed in neonatal birth length and head 
circumference of study group as compared to control group. Clapp and Collings et al also reported similar results. $^{21,26}$ NICU admission rate was $49.18 \%$ in control group and $14.75 \%$ in study group, found to be statistically significant. Previous studies conducted did not mention any comparison on the NICU stay of the new-borns.

\section{CONCLUSIONS}

Antenatal exercises leads to improvement of a majority of pulmonary functions. Labour and neonatal outcome is also being positively affected by exercise. Maternal weight gain was significantly greater in study group than control group. Incidence of preterm labour was not increased. Chances of spontaneous labour were increased with decreased number of induction of labour and less need for labour augmentation. Women who exercised had lower frequency of operative vaginal and caesarean deliveries. Duration of labour was shortened. Meconium stained liquor was lesser and APGAR score at 1 minute was significantly greater. Birth weight, birth length and head circumference of new-borns were also significantly higher with significantly lesser rates of NICU admissions in study group compared to control group.

Funding: No funding sources

Conflict of interest: None declared

Ethical approval: The study was approved by the Institutional Ethics Committee

\section{REFERENCES}

1. Bungum TJ, Peaslee OL, Jackson AW, et al. Exercise during pregnancy and type of delivery in nulliparae. $\mathbf{J}$ Obstet Gynaecol Neonatal Nurs. 2000;29:258-61.

2. Neeraj Sodhi C, Pramod J, Singh J, Kaur V. Effect of advanced uncomplicated pregnancy on pulmonary function parameters of North Indian subjects. Indian J Physiol Pharmacol. 2010;54(1):69-72.

3. Cunningham G, Leveno KJ, Bloom SL, Hauth JC, Gilstrap LC, Wenstrom KD. Maternal physiology. In: Cunningham G, Leveno KJ, Bloom SL, Hauth JC, Gilstrap LC, Wenstrom KD, eds. William Obstetrics, 23rd ed. New York: McGraw-Hill. 2005:105-35.

4. ACOG Committee Obstetric Practice. ACOG Committee opinion. Number 267, January 2002: exercise during pregnancy and the postpartum period. Obstet Gynecol. 2002;99(1):171-3.

5. Kardel KR, Johansen B, Voldner N, Iversen PO, Henriksen T. Association between aerobic fitness in late pregnancy and duration of labor in nulliparous women. Acta Obstet Gynecol Scand. 2009;88(8):94852.

6. Pate RR, Pratt M, Blair SN, Haskell WL, Macera CA, Bouchard C, et al. Physical activity and public health. A recommendation from the Centers for Disease Control and Prevention and the American College of Sports Medicine. JAMA. 1995;273(5):402-7.

7. Macera CA, Ham SA, Yore MM, Jones DA, Ainsworth BE, Kimsey CD, Kohl HW 3rd.
Prevalence of physical activity in the United States: Behavioral Risk Factor Surveillance System, 2001. Prev Chronic Dis. 2005;2(2):A17.

8. Kramer MS. Aerobic exercise for women during pregnancy. Cochrane Database Syst Rev. 2010;(6).

9. Shashikala L, Sarath R. Effects of exercise on pulmonary function test. Indian J Fundamental App Life Sci. 2011;1:230-1.

10. Grindheim G, Toska K, Estensen ME, Rosseland LA. Changes in pulmonary function during pregnancy: a longitudinal cohort study. BJOG. 2012;119(1):94-101

11. Puranik BM, Kaore SB, Kurhade GA, Agrawal SD, Patwardhan SA, Kher JR. A longitudinal study of pulmonary function tests during pregnancy. Indian $\mathbf{J}$ Physiol Pharmacol. 1994;38(2):129-32.

12. Sroczyński T. Evaluation of respiratory tract function in healthy women in the last month of uncomplicated pregnancy. Ann Acad Med Stetin. 2002;48:331-50.

13. Phatak MS, Kurhade GA. A longitudinal study of antenatal changes in lung function tests and importance of postpartum exercises in their recovery. Indian J Physiol Pharmacol. 2003;47(3):352-6.

14. Harirah HM, Donia SE, Nasrallah FK, Saade GR, Belfort MA. Effect of gestational age and position on peak expiratory flow rate: a longitudinal study. Obstet Gynecol. 2005;105(2):372-6.

15. Deshpande H, Makkar C, Dahiya P. A study of pulmonary function tests in different stages of pregnancy. Int J Biol Med Res. 2013;4:2713-6.

16. Gupta L, Dixit R. Study of pulmonary function tests in normal pregnant women of third trimester. IMJ. 2011;105(2):67-70.

17. Barakat R, Stirling JR, Lucia A. Does exercise training during pregnancy affect gestational age? A randomised controlled trial. $\mathrm{Br} \mathrm{J}$ Sports Med. 2008;42(8):674-8.

18. Dias LA, Driusso P, Aita DL, Quintana SM, Bo K, Ferreira $\mathrm{CH}$. Effect of pelvic floor muscle training on labour and newborn outcomes: a randomized controlled trial. Rev Bras Fisioter. 2011;15(6):487-93.

19. Price BB, Amini SB, Kappeler K. Exercise in Pregnancy: Effect on Fitness and Obstetric OutcomesA Randomized Trial. Med Sci Sports Exerc. 2012;44:2263-69.

20. Bechman CR, Beckmann CA. Effect of a structured antepartum exercise programme on pregnancy and labour outcome in primiparas. $\mathrm{J}$ Reprod Med. 1990;35:704-9.

21. Clapp JF III. The course of labor after endurance exercises during pregnancy. Am J Obstet Gynecol. 1990;163:1799-805.

22. Rad LS, Jahanshiri A. Effect of a period of exercise during pregnancy on certain delivery parameters. Eur J Exp Biol. 2013;3:78-85.

23. Forouhari S, Yazdanpanahi Z, Parsanezhad ME, Raigan-Shirazi M. The effects of regular exercise on pregnancy outcome. Iranian Red Cres Med J. 2009;11:57-60.

24. Melzer K, Schutz Y, Soehnchen N, Othenin-Girard V, Martinez de Tejada B, Irion $\mathrm{O}$, et al. Effects of 
recommended levels of physical activity on pregnancy outcomes. Am J Obstet Gynecol. 2010;202(3):266.

25. Magann EF, Evans SF, Weitz B, Newnham J. Antepartum, intrapartum, and neonatal significance of exercise on healthy low-risk pregnant working women. Obstet Gynecol. 2002;99(3):466-72.

26. Collings CA, Curet LB, Mullin JP. Maternal and fetal responses to maternal aerobic exercise program. Am J Obstet Gynaecol. 1983;145:702-7.

27. Kardel KR, Kase T. Training in pregnant women: effect on fetal development and birth. Am J Obstet Gynecol. 1998;178:280-6.

28. Baciuk EP, Pereira RI, Cecatti JG, Braga AF, Cavalcante SR. Water aerobics in pregnancy: Cardiovascular response, labor and neonatal outcomes. Reprod Health. 2008;5:10.

29. Agur W, Steggles P, Waterfield M, Freeman R. Does antenatal pelvic floor muscle training affect the outcome of labour? A randomised controlled trial. Int Urogynecol J Pelvic Floor Dysfunct. 2008;19(1):85-8.

30. Saftlas AF, Logsden-Sackett N, Wang W, Woolson R, Bracken MB. Work, leisure-time physical activity, and risk of preeclampsia and gestational hypertension. Am J Epidemiol. 2004;160(8):758-65.

31. Goodwin A, Astbury J, McMeeken J. Body image and psychological well-being in pregnancy. A comparison of exercisers and non-exercisers. Aust N Z J Obstet Gynaecol. 2000;40(4):442-7.

32. Horns PN, Ratcliffe LP, Leggett JC, Swanson MS. Pregnancy outcomes among active and sedentary primiparous women. J Obstet Gynecol Neonatal Nurs. 1996;25(1):49-54.

33. Hatch MC, Shu XO, McLean DE, Levin B, Begg M, Reuss L, Susser M. Maternal exercise during pregnancy, physical fitness, and fetal growth. Am J Epidemiol. 1993;137(10):1105-14.

Cite this article as: Jain $P$, Srivastava $H$, Goel N, Khaliq F, Dewan P, Sharma R, Bhartiya V. Effect of antenatal exercises on pulmonary functions and labour outcome in uncomplicated primigravida women: a randomized controlled study. Int J Reprod Contracept Obstet Gynecol 2015;4:1478-84. 